\title{
The social determinants of psychosis in migrant and ethnic minority populations: a public health tragedy
}

\author{
C. Morgan ${ }^{1 *}$ and G. Hutchinson ${ }^{2}$ \\ ${ }^{1}$ NIHR Biomedical Research Centre, and Centre for Public Mental Health, Health Service and Population Research Department, Institute of \\ Psychiatry, King's College, London, UK \\ ${ }^{2}$ Psychiatry Unit, Department of Clinical Medical Sciences, University of the West Indies, Mount Hope, Champs Fleurs, Trinidad
}

\begin{abstract}
High rates of schizophrenia and other psychoses have been repeatedly found in migrant populations. However, the development of public health responses has been hindered by unfounded claims that the high rates are an artefact of misdiagnosis. Recent research implicating exposure to social adversity across the life course as the key explanation for these high rates has the potential to inform initiatives to tackle this major public health problem.
\end{abstract}

Received 5 January 2009; Revised 15 January 2009; Accepted 15 February 2009; First published online 1 April 2009

Key words: Ethnicity, migration, psychosis, public health, social determinants.

\section{Introduction}

Maybe the time has come to work toward prevention of disorder and catastrophe, and not merely towards their control. (Agamben, 2002, p. 11)

It has been reported with remarkable consistency over the past 40 years that rates of schizophrenia and other psychoses are substantially higher in the Black Caribbean and the Black African populations in the UK (Fearon \& Morgan, 2006). In one of the most recent studies, conducted in three UK centres, the incidence of all psychoses was four to six times higher in these populations, compared with the White population (Fearon et al. 2006). There is parallel evidence of increased rates of schizophrenia in migrant and ethnic minority groups in other European countries (CantorGraae \& Selten, 2005) and in African-Americans in the USA (Bresnahan et al. 2007). Is this is a genuine and major public health problem, of concern globally, or one that that has been artificially created by psychiatry's inability to objectify diagnoses in different populations?

\section{Artefact or real health disparity?}

It is in the UK that this issue has been most intensively studied. Here, the veracity of reported high

* Address for correspondence: C. Morgan, Ph.D., Centre for Public Mental Health, Health Service and Population Research Department, Box 33, Institute of Psychiatry, De Crespigny Park, London SE5 8AF, UK.

(Email : spjucrm@iop.kcl.ac.uk) rates of psychosis in Black populations has been the subject of acrimonious debate, the fundamental critique being that they are an artefact of misdiagnosis. Similar debates have occurred in the USA (Williams \& Earl, 2007). In brief, the argument is that emotional distress arising from difficult life circumstances in Black populations is misconstrued as psychosis by predominantly White psychiatrists influenced by negative cultural stereotypes of Black people (Fernando, 1991). In the UK this issue has become further entangled with discussions of access to, and quality of, care for Black Caribbean and Black African patients. It is well established that patients from these groups are more likely to access care through a criminal justice agency and to be compulsorily admitted to hospital, with further suggestions of dissatisfaction with, and disengagement from, ongoing care (Morgan et al. 2004). For some, perceived misdiagnosis and poor quality care are part of the same problem-institutional racism in psychiatry (Patel \& Heginbotham, 2007).

This perspective has had a significant impact in the wider policy and advocacy arenas, ensuring that responses have focused primarily on reforming psychiatric practice. However, despite persistent doubts, there is no evidence that the reported high rates are a function of widespread misdiagnosis (Selten \& Hoek, 2008). More recent studies, which have used standardized procedures for assessing symptomatology, with diagnosis being made blind to ethnicity, have continued to report elevated rates, and similar methods do not find comparably elevated rates in other UK 


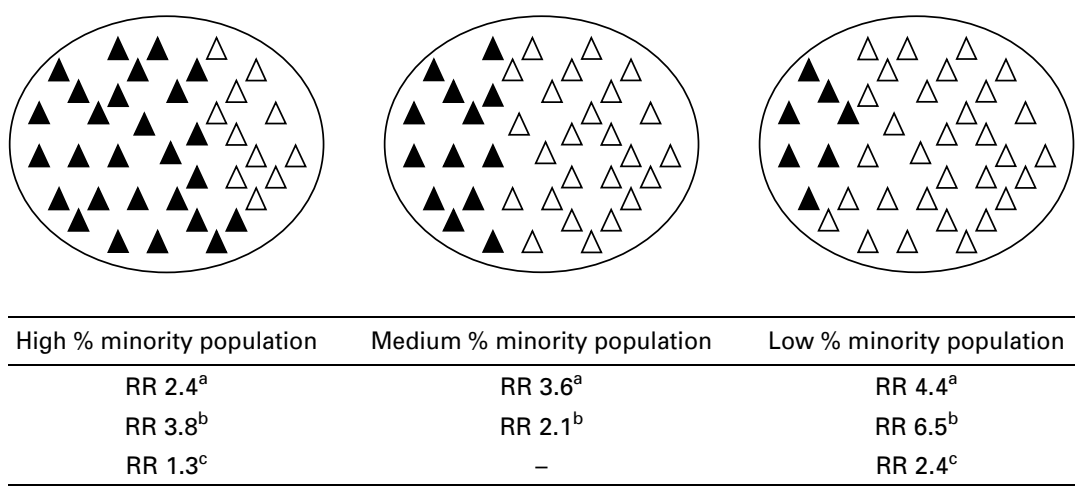

Fig. 1. Rate ratios for schizophrenia by ethnic density in recent studies. RR, rate ratio (migrant or ethnic group versus white).

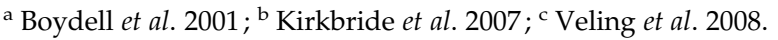

ethnic minority groups or in the Caribbean (Fearon \& Morgan, 2006). An important consequence of conflating issues of service use and population rates of disorder is that there has been no single policy initiative directed at reducing the high rates of psychosis in these populations, in the UK or elsewhere. A crucial public and social health problem has been obscured and ignored.

\section{Understanding the high rates}

The development of appropriate public health strategies for reducing these high rates depends on a clearer understanding of their origins. Recent research provides important clues, primarily in relation to the UK Black Caribbean population.

A series of findings from the Aetiology and Ethnicity in Schizophrenia and Other Psychoses (AESOP) study, for example, link indicators of childhood and adult disadvantage with psychosis in general and with high rates in the UK Caribbean population in particular. To take one example, this study found that long-term separation from a parent before the age of 16 years (a marker of childhood disadvantage, indexing exposure to intra-familial conflict, financial hardship, and housing instability) was around three times more common in those with a first episode of psychosis compared with population-based controls, after taking account of possible confounders. Importantly, although the effect of separation on the odds of psychosis was similar for White British and Black Caribbean individuals, separations were much more common for Black Caribbean (e.g. 31\% Black Caribbean controls versus $18 \%$ White British controls, $p=0.03$ ) (Morgan et al. 2007). This pattern (i.e. a similar effect size in both groups, a higher prevalence in the Black Caribbean population) was also evident for a number of indicators of adult social disadvantage and isolation (both recent and long-standing), including unemployment, housing instability, and limited social networks (Morgan et al. 2008). These findings suggest that the high rates are a function of a greater prevalence of social risk factors for psychosis in the UK Black Caribbean population.

High levels of social disadvantage in migrant and ethnic minority groups may reflect a subtle racism institutionalized in social structures that constrain access to opportunities and resources. Related to this, there is some evidence that direct exposure to discrimination is associated with an increased likelihood of psychosis. For example, Karlsen \& Nazroo (2002), in an analysis of data from the UK Fourth National Survey of Ethnic Minorities, found that both socio-economic position and the experience of discrimination were independent predictors of psychosis in Black and Minority Ethnic groups. Perhaps most intriguing is the finding that the relative risk of schizophrenia increases as Black Caribbean people in the UK form a decreasing proportion of the local population (Boydell et al. 2001; Kirkbride et al. 2007); that is, the less ethnically dense an area, the higher the rates of psychosis. This finding has recently been replicated for migrant groups in The Netherlands (Veling et al. 2008) (Fig. 1). It has been hypothesized that living in high ethnic density areas may provide a buffer against the adverse effects of disadvantage and discrimination, perhaps through a greater availability of social support. Further research is needed to test this directly. What is most notable, however, is that such a social patterning of risk defies ready explanation, or even plausible speculation, in terms of social drift or known biological risk factors.

At the same time, there has been no similar accumulation of evidence implicating known biological risk factors. For example, there is no evidence that rates of disorder are elevated in the countries of origin from which these populations migrated, a finding that has been interpreted as showing that population 
differences in genetic risk are unlikely to account for the increased incidence (Fearon \& Morgan, 2006). Furthermore, there is no evidence that obstetric complications are more common in the Caribbean population (Hutchinson et al. 1997) and data from the AESOP study show neither a greater effect for neurodevelopmental markers nor a greater prevalence in the Black Caribbean group (e.g. Dean et al. 2007). There is some evidence that structural brain abnormalities may be more marked in Black Caribbean cases relative to Black Caribbean controls (K. Morgan et al. unpublished observations). This could, however, be a reflection of the impact of chronic adversity over the life course or of differential prescription of antipsychotic medication.

\section{Social determinants of psychosis}

There has been a recent upsurge of evidence implicating social experiences and environments in the aetiology of psychosis including: urban living (Krabbendam \& van Os, 2005), childhood adversity and trauma (Morgan \& Fisher, 2007), and adult daily hassles and stress (Myin-Germeys \& van Os, 2007). This research, in using more sophisticated measures and more effective designs, has addressed many of the limitations of earlier studies of socio-economic status and psychosis. The evidence now suggests that these exposures predate onset, and increase risk in a doseresponse fashion. Perhaps most importantly, several plausible biological and psychological mechanisms have been identified (Collip et al. 2008). For example, there is evidence from both animal and human studies that exposure to social adversity (in various forms) can lead to a sensitization of the mesolimbic dopaminergic system. This is particularly noteworthy given the resurgence of interest in the role of dopamine in the genesis of psychotic experiences (Di Forti et al. 2007). There is also emerging evidence that psychosis is associated with increased activation of the hypothalamic-pituitary-adrenal (HPA) axis (Pariante et al. 2005), and that early adversity is associated with alterations in brain structure and function in areas that have been implicated in schizophrenia (e.g. hippocampus, corpus callosum, amygdale) (Teicher et al. 2003). Perhaps the most significant recent advance is the realization that genes and environment frequently interact to shape adult outcomes, including psychosis (van Os et al. 2003). From this, it is plausible that, from a similar base level of biological and genetic vulnerability, greater exposure to social adversity (or social defeat; Selten \& Cantor-Graae, 2005) over the life course, in the absence of supportive buffers, could substantially increase population rates of disorder, as in migrant populations.

\section{Wider context}

This issue needs to be seen in a wider context. The Black Caribbean population is one of the most disadvantaged in the UK. There are high rates of many indices of disadvantaged social outcomes, for example school exclusions (Wright et al. 2005), unemployment (Berthoud, 1999) and substance use (Jayakody et al. 2006), each of which in turn becomes a risk factor for further poor outcomes. Much the same holds for many migrant and ethnic minority populations around the world. These processes begin at an early stage. It is well established that early disadvantage sets a developmental trajectory characterized by increased likelihood of exposure to subsequent adversities, each of which is likely to have a compounding effect (Engle et al. 2007). To paraphrase Jones et al. (1994), early disadvantage sets in train a cascade of problematic social development, one consequence of which may be an increased risk of psychosis. Addressing the high rates, therefore, has to be part of a wider social strategy. If institutional racism is relevant, it is that which affects every institution in society, structuring access to decent housing and heating, to an adequate education, to employment and effective social services. The problem is not 'in' migrant populations, it is not 'in' psychiatry. The problem is 'in' society.

\section{Conclusion and implications}

Compared with White people in the UK, upwards of five times more Black Caribbean and Black African people develop schizophrenia and other psychoses year on year, disorders that impact not just on the individual but also on families and the wider society, often leading to long-term suffering and social exclusion. There is also an excess in many other migrant and ethnic minority groups in Europe and the USA. This is a public health tragedy, and one that remains neglected. There is now an urgent need for concerted public policy initiatives in the UK and elsewhere aimed at preventing the factors that are associated with these increased rates, particularly in childhood. Initiatives designed to prevent social exclusion and halt problematic social development (e.g. Sure Start in the UK, neighbourhood regeneration) are more imperative and need to be targeted at those individuals and populations most at risk. In the same way that improved sanitation, hygiene and nutrition revolutionized physical health, mitigating the effects of social disadvantage may achieve the same for serious mental illness, especially in the most vulnerable groups. 


\section{Declaration of Interest}

None.

\section{References}

Agamben G (2002). Security and terror. Theory and Event 5, 9-11.

Berthoud R (1999). Young Caribbean Men and the Labour Market: A Comparison with Other Ethnic Groups. Joseph Rowntree Foundation: London.

Boydell J, van Os J, McKenzie K, Allardyce J, Goel R, McCreadie RG, Murray R (2001). Incidence of schizophrenia in ethnic minorities in London: ecological study into interactions with environment. British Medical Journal 323, 1336-1338.

Bresnahan M, Begg MD, Brown A, Schaefer C, Sohler N, Insel B, Vella L, Susser E (2007). Race and risk of schizophrenia in a US birth cohort: another example of a health disparity? International Journal of Epidemiology 36, 752-758.

Cantor-Graae E, Selten JP (2005). Schizophrenia and migration: a meta-analysis and review. American Journal of Psychiatry 162, 12-24.

Collip D, Myin-Germeys I, van Os J (2008). Does the concept of 'sensitisation' provide a plausible mechanism for the putative link between the environment and schizophrenia. Schizophrenia Bulletin 34, 220-225.

Dean K, Dazzan P, Lloyd T, Morgan C, Morgan K, Doody G, Hutchinson G, Orr K, Jones P, Murray R, Fearon P (2007). Minor physical anomalies across ethnic groups in a first episode psychosis sample. Schizophrenia Research 89, 86-90.

Di Forti M, Lappin JM, Murray RM (2007). Risk factors for schizophrenia: all roads lead to dopamine. European Neuropsychopharmacology 17, s101-s107.

Engle PL, Black MM, Behrman JR, de Mello MC, Gertler PJ, Kapiriri L, Martorell R, Young ME; the International Child Development Steering Group (2007). Strategies to avoid the loss of developmental potential in more than 200 million children in the developing world. Lancet 369, 229-242.

Fearon P, Kirkbride JK, Morgan C, Dazzan P, Morgan K, Lloyd T, Hutchinson G, Tarrant J, Fung A, Holloway J, Mallett R, Harrison G, Leff J, Jones P, Murray R (2006). Incidence of schizophrenia and other psychoses in ethnic minority groups: results from the MRC AESOP study. Psychological Medicine 36, 1541-1550.

Fearon P, Morgan C (2006). Environmental factors in schizophrenia: the role of migrant studies. Schizophrenia Bulletin 32, 405-408.

Fernando S (1991). Mental Health, Race and Culture. Macmillan: London.

Hutchinson G, Takei N, Bhugra D, Fahy TA, Gilvary C, Mallett R, Moran P, Leff J, Murray RM (1997). Increased rate of psychosis among African-Caribbeans in Britain is not due to an excess of pregnancy and birth complications. British Journal of Psychiatry 171, 145-147.

Jayakody AA, Viner RM, Haines MM, Bhui KS, Head JA, Taylor SJ, Booy R, Klineberg E, Clark C, Stansfeld SA
(2006). Illicit and traditional drug use among ethnic minority adolescents in East London. Public Health 120 329-338.

Jones P, Rogers B, Murray R, Marmot M (1994). Child developmental risk factors for adult schizophrenia in the British 1946 birth cohort. Lancet 344, 1398-1402.

Karlsen S, Nazroo J (2002). Relation between racial discrimination, social class, and health among ethnic minority groups. American Journal of Public Health 92, 624-631.

Kirkbride J, Morgan C, Fearon P, Dazzan P, Murray RM, Jones P (2007). Neighbourhood-level effects on psychoses: re-examining the role of context. Psychological Medicine 37, 1413-1425.

Krabbendam L, van Os J (2005). Schizophrenia and urbanicity: a major environmental influence - conditional on genetic risk. Schizophrenia Bulletin 31, 795-799.

Morgan C, Fisher H (2007). Environmental factors in schizophrenia: childhood trauma - a critical review. Schizophrenia Bulletin 33, 3-10.

Morgan C, Kirkbride J, Hutchinson G, Craig T, Morgan K, Dazzan P, Boydell J, Doody G, Jones P, Murray R, Leff J, Fearon P (2008). Cumulative social disadvantage, ethnicity and first-episode psychosis: a case-control study. Psychological Medicine 38, 1701-1716.

Morgan C, Kirkbride J, Leff J, Craig T, Hutchinson G, McKenzie K, Morgan K, Dazzan P, Doody G, Jones P, Murray R, Fearon P (2007). Parental separation, loss and psychosis in different ethnic groups: a case-control study. Psychological Medicine 37, 495-505.

Morgan C, Mallett R, Hutchinson G, Leff J (2004). Negative pathways to psychiatric care and ethnicity: the bridge between social science and psychiatry. Social Science and Medicine 58, 739-752.

Myin-Germeys I, van Os J (2007). Stress-reactivity in psychosis: evidence for an affective pathway to psychosis. Clinical Psychology Review 27, 409-424.

Pariante CM, Dazzan P, Danese A, Morgan KD, Brudaglio F, Morgan C, Fearon P, Orr K, Hutchinson G, Pantelis C, Velakoulis D, Jones PB, Leff J, Murray RM (2005). Increased pituitary volume in antipsychoticfree and antipsychotic-treated patients of the AESOP first-onset psychosis study. Neuropsychopharmacology 30, 1923-1931.

Patel K, Heginbotham C (2007). Institutional racism in psychiatry does not imply racism in individual psychiatrists: Commentary on ... Institutional racism in psychiatry. Psychiatric Bulletin 31,367-368.

Selten JP, Cantor-Graae E (2005). Social defeat: risk factor for psychosis. British Journal of Psychiatry 187, 101-102.

Selten J-P, Hoek HW (2008). Does misdiagnosis explain the schizophrenia epidemic among immigrants from developing countries to Western Europe? Social Psychiatry and Psychiatric Epidemiology 43, 937-939.

Teicher MH, Andersen SL, Polcari A, Anderson CM, Navalta CP, Kim DM (2003). The neurobiological consequences of early stress and childhood maltreatment. Neuroscience and Biobehavioural Reviews 27, 33-44. 
van Os J, Hanssen M, Bak M, Bijl RV, Vollebergh W (2003).

Do urbanicity and familial liability coparticipate in causing psychosis? American Journal of Psychiatry 160, 477-482.

Veling W, Susser E, van Os J, Mackenbach JP, Selten J-P, Hoek HW (2008). Ethnic density of neighbourhoods and incidence of psychotic disorders among immigrants. American Journal of Psychiatry 165, 66-73.
Williams DR, Earl TR (2007). Commentary. Race and mental health: more questions than answers. International Journal of Epidemiology 36, 758-760.

Wright C, Standen P, John G, German G, Patel T (2005). School Exclusion and Transition into Adulthood in AfricanCaribbean Communities. Joseph Rowntree Foundation: London. 